\title{
Patency of the Anterior Choroidal Artery after Flow-Diversion Treatment of Internal Carotid Artery Aneurysms
}

\author{
W. Brinjikji, D.F. Kallmes, H.J. Cloft, and G. Lanzino
}

\begin{abstract}
BACKGROUND AND PURPOSE: Treatment of cerebral aneurysms with flow diverters often mandates placement of the device across the ostia of major branches of the internal carotid artery. We determined the patency rates of the anterior choroidal artery after placement of flow-diversion devices across its ostium.
\end{abstract}

MATERIALS AND METHODS: We analyzed a consecutive series of patients in whom a Pipeline Embolization Device was placed across the ostium of an angiographically visible anterior choroidal artery while treating the target aneurysm. Patency of the anterior choroidal artery after Pipeline Embolization Device placement was determined at immediate postoperative and follow-up angiography. Data on pretreatment aneurysm rupture status, concomitant coiling, number of Pipeline Embolization Devices used, neurologic status at follow-up, and follow-up MR imaging/CT findings were collected.

RESULTS: Fifteen patients with 15 treated aneurysms were included in this study. In the immediate postprocedural setting, the anterior choroidal artery was patent on posttreatment angiography for all 15 patients. Of the 14 patients with follow-up angiography at least 6 months after Pipeline Embolization Device placement, 1 (7\%) had occlusion of the anterior choroidal artery and 14 had a patent anterior choroidal artery (93\%). No patients had new neurologic symptoms or stroke related to anterior choroidal artery occlusion at follow-up. Of the 9 patients with follow-up CT or MR imaging, none had infarction in the vascular territory of the anterior choroidal artery.

CONCLUSIONS: In this small study, placement of a Pipeline Embolization Device across the anterior choroidal artery ostium resulted in occlusion of the artery in only 1 patient. It was not associated with ischemic changes in the distribution of the anterior choroidal artery in any patient.

ABBREVIATIONS: AchoA = anterior choroidal artery; PED = Pipeline Embolization Device

$\mathbf{F}$ ow-diverter devices such as the Pipeline Embolization Device (PED; Covidien, Irvine, California) are increasingly being used in the embolization of intracranial aneurysms as both alternatives and adjuncts to endovascular coiling. ${ }^{1-4}$ Flow diverters limit aneurysmal blood flow but maintain blood flow into large vessels and perforating vessels covered by the device. ${ }^{5}$ Although many in vitro and experimental models have demonstrated long-term patency rates of branch vessels covered by the PED, the long-term patency of major branch vessels is not well-established. ${ }^{6-8}$ In this study, we assessed the immediate and long-term patency rates of

Received May 29, 2014; accepted after revision August 13.

From the Departments of Radiology (W.B., D.F.K., H.J.C., G.L.) and Neurosurgery (D.F.K., H.J.C., G.L.), Mayo Clinic, Rochester, Minnesota.

Please address correspondence to Waleed Brinjikji, MD, Department of Radiology, Mayo Clinic, 200 1st St SW, Rochester, MN 55901; e-mail: Brinjikji.waleed@ mayo.edu

http://dx.doi.org/10.3174/ajnr.A4139 the anterior choroidal artery (AchoA) in patients following the placement of a PED across the AchoA ostium.

\section{MATERIALS AND METHODS}

After institutional review board approval, we examined a consecutive series of patients undergoing treatment of intracranial aneurysms with the PED, in which the PED was placed across the ostium of the anterior choroidal artery, from January 2010 to December 2013. Current on-label use of PEDs is for aneurysms of $>10 \mathrm{~mm}$ in diameter with a neck of $>4 \mathrm{~mm}$ in the ICA up to but not including the posterior communicating artery. In this study, we used the PED off-label for wide-neck aneurysms considered likely to require stent coiling.

All patients undergoing treatment were premedicated with aspirin and clopidogrel, and full anticoagulation was maintained during the procedure (target activated clotting time between 250 and 300 seconds). Following the procedure, patients were maintained on dual antiplatelet therapy for 3 months. After 3 months, 
Table 1: Patient characteristics

\begin{tabular}{clllcc}
\hline $\begin{array}{c}\text { Patient } \\
\text { No. }\end{array}$ & Presentation & Side & Aneurysm Location & $\begin{array}{c}\text { Prior } \\
\text { Coiling }\end{array}$ & $\begin{array}{c}\text { Aneurysm } \\
\text { Size (mm) }\end{array}$ \\
\hline 1 & VF deficit & Left & Carotid terminus & Yes & 25 \\
2 & Headache & Left & PcomA & No & 27 \\
3 & SAH & Left & ICA blister & No & 4 \\
4 & Asymptomatic & Right & PcomA & No & 3 \\
5 & Prior SAH & Left & Paraclinoid & Yes & 13 \\
6 & Headache & Left & PcomA & Yes & 16 \\
7 & Prior SAH & Left & Carotid terminus & Yes & 20 \\
8 & Asymptomatic & Left & PcomA & No & 7 \\
9 & Asymptomatic & Left & AchoA & No & 11 \\
10 & Symptomatic & Left & PcomA & No & 20 \\
11 & Prior SAH & Right & PcomA & Yes & 10 \\
12 & Asymptomatic & Left & PcomA & No & 11 \\
13 & Asymptomatic & Left & Paraclinoid & No & 13 \\
14 & Prior SAH & Left & Paraclinoid & Yes & 16 \\
15 & Asymptomatic & Right & PcomA & No & 4 \\
\hline
\end{tabular}

Note:-VF indicates visual field; PcomA, posterior communicating artery.

clopidogrel was discontinued and aspirin was continued indefinitely. This antiplatelet regimen was the same in all patients, and no platelet responsiveness studies were used in these cases. All the procedures were performed with the patient under general endotracheal anesthesia. A bi- or triaxial access technique and, in all cases, a Marksman microcatheter (Covidien) were used to obtain distal access past the segment of the vessel harboring the target aneurysm. Pipeline Embolization Devices were sized to match the maximum diameter of the target vessel. One or multiple devices were used at the discretion of the operators to maximize the changes of complete aneurysm occlusion and/or to ensure adequate coverage of the aneurysm neck and a segment of the parent artery proximal and distal to it. Digital subtraction angiography was performed at 2 frames per section before and following placement of the PED.

Determination of AchoA patency by all authors was made for each patient immediately after the original procedure and at the follow-up angiography performed furthest from the initial procedure. Note was also made of any subjectively determined change in flow patterns (slowing of angiographic flow after PED deployment and/or at follow-up). All patients underwent a detailed clinical examination before the procedure, immediately after the procedure, the following day, and at each corresponding follow-up angiography. In addition to AchoA patency, patient age, sex, presentation, aneurysm size, previous coiling, neurologic status on last follow-up, and follow-up MR imaging and CT results were collected. Postoperative follow-up CT and MR imaging results were divided into 2 time periods: 1 ) within 1 month of the procedure, and 2) $>1$ month after the procedure. Infarction location in the AchoA distribution was defined as infarctions localized to the posterior limb of the internal capsule and thalamus as described by Damasio. ${ }^{9}$ All images were reviewed by 2 neuroradiologists. Patient neurologic status on last follow-up was scored by using the modified Rankin Scale and was assessed on follow-up with the Neurosurgery Department.

\section{Statistical Analysis}

Summary statistics are presented for all data available by using means \pm SDs for continuous variables and frequency tabulations for categoric variables. All statistical analyses were performed by using JMP 9.0 (SAS Institute, Cary, North Carolina).

\section{RESULTS \\ Patient and Aneurysm \\ Characteristics}

Fifteen patients (12 women and 3 men) with 15 PED-treated aneurysms were included in this study. Mean patient age was $56.0 \pm 14.4$ years (range, 34-75 years). Aneurysm sizes ranged from 3 to $27 \mathrm{~mm}$ with a mean of $13.0 \pm 7.4 \mathrm{~mm}$. Twelve aneurysms were unruptured; 3 were previously ruptured and were treated with coil embolization in the acute phase and staged Pipeline placement after patients had recovered from the acute SAH. Two patients had their aneurysm treated after it was discovered during treatment of a different, ruptured aneurysm. Three patients with unruptured aneurysms had prior aneurysm coiling. One PED was placed in 11 patients. These data are summarized in Table 1.

\section{Clinical and Angiographic Follow-Up}

Initial postoperative angiography demonstrated patency of the AchoA in all 15 patients. One patient (patient 3 ) died 10 days after PED placement from intraparenchymal hemorrhage but had a follow-up angiography on postprocedural day 1, which demonstrated a patent AchoA. Of the remaining 14 patients, angiographic follow-up times ranged from 6 to 30 months, with a mean follow-up of $12.0 \pm 7.2$ months. Of these 14 patients, 13 had a patent AchoA (93\%) and 1 had occlusion of the AchoA (7\%) (Figure). There were no instances of slowing of flow in the AchoA.

The mean clinical follow-up time was $12 \pm 8.6$ months, with a minimum follow-up of 10 days and a maximum follow-up of 30 months. One patient (patient 3) presented with SAH resulting from an ICA blister aneurysm and was treated in the acute phase with a PED. One day following the procedure, this patient was found to have multiple watershed infarcts in the bilateral anterior cerebral artery/MCA distribution and a large frontal lobe intraparenchymal hematoma ipsilateral to the treated aneurysm. This patient died 10 days after the procedure because of the intraparenchymal hematoma. Of the remaining patients, the mRS scores at last follow-up ranged from 0 to 2 (mean $=1 \pm 0.76$ ). None of these patients had neurologic complications related to the procedure. No patients had clinical strokes in the perioperative period or during long-term follow-up. The most common cause for an mRS of $>0$ was headache. The 1 patient with occlusion of the AchoA had an mRS of zero at 6 months and experienced no symptoms related to AchoA occlusion. These data are summarized in Table 2.

\section{MR Imaging/CT Follow-Up}

Eight patients had postoperative MR imaging or CT within 1 month of PED placement. Patient 3, described above, had an intraparenchymal hemorrhage with multiple bilateral watershed infarcts on CT on postoperative day 1 . Seven patients underwent early postoperative MRI (1-5 days postopera- 

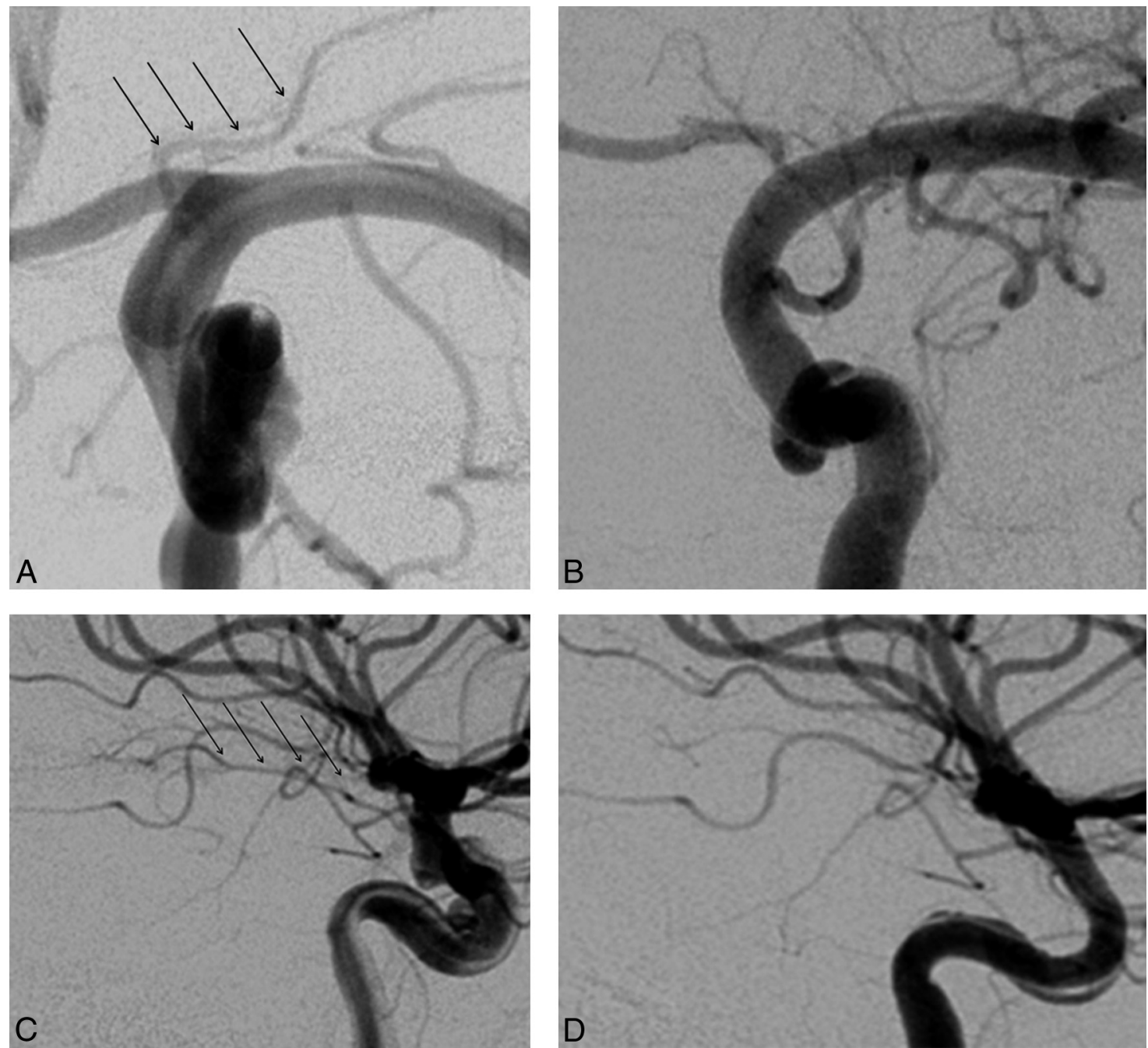

FIGURE. Occlusion of anterior choroidal artery on follow-up angiography. A, Anteroposterior view of the anterior choroidal artery on pretreatment angiography demonstrates a patent anterior choroidal artery (black arrows). B, Follow-up angiogram 7 months posttreatment demonstrates absence of filling of the anterior choroidal artery. C, Lateral view of the anterior choroidal artery on pretreatment angiography demonstrates that it is patent (black arrows). D, Follow-up angiogram 7 months posttreatment demonstrates absence of filling of the anterior choroidal artery.

Table 2: Angiographic results

\begin{tabular}{cccccl}
\hline $\begin{array}{c}\text { Patient } \\
\text { No. }\end{array}$ & $\begin{array}{c}\text { No. of } \\
\text { Devices }\end{array}$ & $\begin{array}{c}\text { Immediate } \\
\text { Postangiography } \\
\text { AchoA Patency }\end{array}$ & $\begin{array}{c}\text { Long-Term } \\
\text { Patency }\end{array}$ & $\begin{array}{c}\text { Angiographic } \\
\text { Follow-Up (mo) }\end{array}$ & $\begin{array}{c}\text { Aneurysm Occlusion, } \\
\text { Last Follow-Up }\end{array}$ \\
\hline 1 & 3 & Patent & Patent & 14 & Occluded \\
2 & 2 & Patent & Patent & 30 & Residual aneurysm \\
3 & 1 & Patent & NA & 1 day & NA \\
4 & 2 & Patent & Patent & 25 & Residual aneurysm \\
5 & 1 & Patent & Patient & 13 & Residual neck \\
6 & 1 & Patent & Patent & 6 & Residual neck \\
7 & 1 & Patent & Patent & 9 & Occluded \\
8 & 1 & Patent & Patent & 12 & Residual aneurysm \\
9 & 1 & Patent & Patent & 12 & Residual aneurysm \\
10 & 2 & Patent & Patent & 12 & Residual aneurysm \\
11 & 1 & Patent & Patent & 6 & Occluded \\
12 & 1 & Patent & Patent & 6 & Occluded \\
13 & 1 & Patent & Patent & 12 & Occluded \\
14 & 1 & Patent & Patent & 6 & Occluded \\
15 & 1 & Patent & Occluded & 7 & Occluded \\
\hline
\end{tabular}

Note:-NA indicates not available; patient died within 10 days of treatment.

tively). Seven patients demonstrated multiple small infarcts, generally in the MCA distribution. No patients had infarcts in the AchoA distribution. Eight patients underwent postopera- tive MR imaging or CT at $>1$ month after PED placement. No patients had permanent neurologic deficits corresponding to the infarct location. These findings are summarized in Table 3.

\section{DISCUSSION}

Our study demonstrated that the ostium of the AchoA can be covered with the PED for aneurysm treatment without resulting in neurologic complications related to AchoA occlusion. Following flow-diverter placement across its ostium, the AchoA was patent in 13 of 14 patients who underwent follow-up angiography at least 6 months after the procedure. Of the patients who underwent postoperative CT or MR imaging, none experienced infarctions that were definitely in the territory of the AchoA. The rarity of angiographic occlusion of the AchoA and lack of neurologic sequelae following placement of the PED across its ostium are 
Table 3: Clinical and MRI/CT Results

\begin{tabular}{|c|c|c|c|c|c|}
\hline $\begin{array}{l}\text { Patient } \\
\text { No. }\end{array}$ & $\begin{array}{l}\text { mRS at Last } \\
\text { Follow-Up }\end{array}$ & Reason for mRS & $\begin{array}{c}\text { Clinical } \\
\text { Follow-Up } \\
\text { Time (mo) }\end{array}$ & $\begin{array}{c}\text { Follow-Up MRI/CT Findings } \\
\text { at }<1 \text { Month }\end{array}$ & $\begin{array}{l}\text { Follow-Up Imaging Findings } \\
\text { at }>1 \text { Month }\end{array}$ \\
\hline 1 & 2 & Headaches & 27 & $\begin{array}{l}\text { MRI: tiny silent infarcts, none in AchoA } \\
\text { territory }\end{array}$ & MRI: no new infarcts \\
\hline 2 & 1 & Abdominal pain & 30 & NA & $\begin{array}{l}\text { CT: tiny infarcts, none in AchoA } \\
\text { territory }\end{array}$ \\
\hline 3 & 6 & Death & 0.3 & $\begin{array}{l}\text { CT: watershed infarcts, intraparenchymal } \\
\text { hemorrhage }\end{array}$ & \\
\hline 4 & 0 & - & 25 & NA & NA \\
\hline 5 & 2 & $\begin{array}{l}\text { CN IV paresis, double } \\
\text { vision }\end{array}$ & 13 & $\begin{array}{l}\text { MRI: tiny silent infarcts, none in AchoA } \\
\text { territory }\end{array}$ & CT: no new infarcts \\
\hline 6 & 0 & - & 6 & $\begin{array}{l}\text { MRI: tiny silent infarcts, none in AchoA } \\
\text { territory }\end{array}$ & MRI: no new infarcts \\
\hline 7 & 1 & Shoulder pain & 9 & $\begin{array}{l}\text { MRI: tiny silent infarcts, none in AchoA } \\
\text { territory }\end{array}$ & MRI: no new infarcts \\
\hline 8 & 0 & & 12 & NA & NA \\
\hline 9 & 1 & Headaches & 12 & NA & NA \\
\hline 10 & 1 & Headaches & 12 & $\begin{array}{l}\text { MRI: tiny silent infarcts, none in AchoA } \\
\text { territory }\end{array}$ & MRI: no new infarcts \\
\hline 11 & 0 & - & 6 & NA & NA \\
\hline 12 & 0 & - & 6 & NA & NA \\
\hline 13 & 0 & - & 12 & NA & CT: no new infarcts \\
\hline 14 & 0 & - & 6 & $\begin{array}{l}\text { MRI: tiny silent infarcts, none in AchoA } \\
\text { territory }\end{array}$ & NA \\
\hline 15 & 0 & - & 7 & $\begin{array}{l}\text { MRI: tiny silent infarcts, none in AchoA } \\
\text { territory }\end{array}$ & MRI: no new infarcts \\
\hline
\end{tabular}

Note:-NA indicates not available; $C N$, cranial nerve.

particularly important, given the large number of aneurysms in the supraclinoid ICA that are amenable to flow-diverter treatment. ${ }^{10}$

Previous clinical, animal, and computational studies have examined the propensity for branch artery occlusion following flow-diversion implantation..$^{5,6,11,12}$ Kallmes et al ${ }^{13,14}$ found that on occlusion of lumbar branch vessels in the rabbit aorta with overlapping flow-diversion devices, these perforating vessels remained patent on follow-up. While a device placed across the origin of a perforating vessel (traditionally considered end vessels with no distal collaterals) may maintain flow across the ostium due to a pressure gradient across its ostium, the same is not true when larger vessels like the ophthalmic artery and the posterior communicating artery (which often have significant distal collateral potential) are covered by these devices. In such cases, the pressure gradient across the device struts is not enough to maintain patent flow due to the opposing effect of the distal collateral flow, which creates a neutral gradient and angiographic occlusion. Puffer et $\mathrm{al}^{15}$ examined ophthalmic artery patency rates following flow-diverter placement and found that nearly $25 \%$ of ophthalmic arteries were occluded on long-term follow-up with no clinical sequelae. Brinjikji et al ${ }^{16}$ demonstrated a long-term occlusion rate of the posterior communicating artery of approximately $27 \%$, with no patients experiencing focal neurologic deficits.

In the case of the anterior choroidal artery, prior studies have demonstrated collateral flow in the setting of chronic ICA occlusion from the lateral posterior choroidal artery, posterior cerebral artery, and posterior communicating artery. Takahashi et $\mathrm{al}^{17} \mathrm{de}-$ scribed 7 cases of retrograde filling of the anterior choroidal artery on vertebral angiography. In most cases, this retrograde filling was demonstrated following thrombotic occlusion of the supraclinoid ICA. The normal AchoA has anastomoses with the posterior com- municating artery and the posterior cerebral artery. Anastomoses with the posterior circulation occur at the level of the choroid plexus, lateral geniculate body, or proximal portions of the posterior cerebral artery. ${ }^{18,19}$

All 6 patients who had MR imaging in the immediate postoperative period had small foci of restricted diffusion. These findings are consistent with those of the coiling literature, in which up to $75 \%$ of patients have high-signal lesions on DWI, most of which are silent infarcts. In a series of 34 consecutive patients undergoing elective coiling for unruptured aneurysms, Matsushige et $\mathrm{al}^{20}$ reported that $76 \%$ of patients had high-signal spots on DWI. Hahnemann et $\mathrm{al}^{21}$ found that nearly two-thirds of patients undergoing stent-assisted coiling had postprocedural ischemic lesions on DWI in a series of 75 patients. Our study is considerably smaller, and further studies reporting the incidence of DWI changes following PED placement are necessary. In all cases, these infarcts were clinically silent.

There was 1 death in our series. The patient had a small ruptured blister aneurysm and was treated in the acute phase with a PED. One day following the procedure, this patient was found to have multiple watershed infarcts in the bilateral anterior cerebral artery/MCA distribution and a large frontal lobe intraparenchymal hematoma ipsilateral to the treated aneurysm. Ruptured blister aneurysms have a very poor natural history and are generally associated with poor clinical outcomes regardless of treatment technique. However, the PED is emerging as a valid therapeutic option for ruptured blister aneurysms of the ICA. Yoon et $\mathrm{al}^{22}$ reported a series of 11 patients treated with the PED for ruptured blister ICA aneurysms. In this series, 3 patients (27\%) had major perioperative ischemic complications and 1 patient died. Further research is needed to determine the role of the PED in the treatment of blister aneurysms. 
Our study was limited by the relatively small number of treated aneurysms. Given the rarity of angiographic occlusion of the anterior choroidal artery in the patients included in our study, we could not determine which variables were associated with anterior choroidal artery occlusion. Therefore, we did not perform any statistical comparisons in our study. Lack of angiographic opacification of a vessel may not indicate complete absence of flow through the vessel. On follow-up angiography, most patients did not have vertebral artery injections; thus, filling of the AchoA from the posterior circulation could not be appreciated. Platelet responsiveness, a potentially important factor in determining arterial patency following PED placement, was not examined in this study. A mean follow-up of approximately 12 months may not have been enough time to determine the long-term patency of the AchoA in these patients; however, the 1 case of angiographic occlusion of the AchoA was demonstrated at the 6-month follow-up.

Another important limitation is our lack of consistent imaging follow-up. Only 9 patients underwent posttreatment imaging. This small number makes it difficult to understand why no patients with a jailed AchoA had an infarct in the AchoA territory. As discussed in an article by Hanley and Lippman-Hand, ${ }^{23}$ a zero numerator does not necessarily mean "no risk." In this article, Hanley and Lippman-Hand discuss the concept of "the rule of 3," essentially stating that the $95 \%$ confidence interval estimate of the risk of an event occurring when the numerator is 0 is, at most, 3 in $n$ ( $n=$ denominator). Thus, with the rule of 3 , the $95 \%$ confidence interval for risk of AchoA territory infarction in our study ranges from $0.0 \%(0 / 9)$ to $33.3 \%(3 / 9)$. These results suggest that further larger studies with consistent imaging follow-up are needed to determine the risk of AchoA territory infarct when the artery is jailed by flow-diverter devices. Last, while none of the silent infarcts seen on MR imaging were in the traditional territory of the AchoA, vascular territories are known to be inexact. However, all images were reviewed by 2 neuroradiologists, and in no cases were there definite findings of AchoA-related infarct.

\section{CONCLUSIONS}

In this small study, placement of a Pipeline Embolization Device across the AchoA ostium resulted in occlusion of the artery in only 1 patient. It was not associated with ischemic changes in the distribution of the AchoA in any patient.

Disclosures: David F. Kallmes_UNRELATED: Board Membership: GE Healthcare, Comments: Advisory Board membership; Consultancy: ev3, Comments: planning and implementation of clinical trials; Grants/Grants Pending: ev3, ${ }^{\star}$ Sequent Medical, ${ }^{*}$ Codman, ${ }^{*}$ MicroVention, ${ }^{*}$ NeuroSigma, ${ }^{*}$ Comments: funding for preclinical and clinical research; Royalties: University of Virginia Patent Foundation, Comments: Spine Fusion. Harry J. Cloft-UNRELATED: Grants/Grants Pending: Cordis Endovascular, ${ }^{*}$ Comments: Site Principal Investigator at enrolling site for Stenting and Angioplasty with Protection in Patients and HIgh Risk for Endarterectomy registry sponsored by Cordis Endovascular. Giuseppe Lanzino-UNRELATED: Consultancy: Covidien*; Payment for Development of Educational Presentations: Codman/Johnson \& Johnson. *Money paid to the institution.

\section{REFERENCES}

1. Brinjikji W, Murad MH, Lanzino G, et al. Endovascular treatment of intracranial aneurysms with flow diverters: a meta-analysis. Stroke 2013;44:442-47

2. Deutschmann HA, Wehrschuetz M, Augustin M, et al. Long-term follow-up after treatment of intracranial aneurysms with the Pipeline embolization device: results from a single center. AJNR Am J Neuroradiol 2012;33:481-86

3. Fischer S, Vajda Z, Aguilar Perez M, et al. Pipeline embolization device (PED) for neurovascular reconstruction: initial experience in the treatment of 101 intracranial aneurysms and dissections. Neuroradiology 2012;54:369-82

4. Saatci I, Yavuz K, Ozer C, et al. Treatment of intracranial aneurysms using the Pipeline flow-diverter embolization device: a single-center experience with long-term follow-up results. AJNR Am J Neuroradiol 2012;33:1436-46

5. D’Urso PI, Lanzino G, Cloft HJ, et al. Flow diversion for intracranial aneurysms: a review. Stroke 2011;42:2363-68

6. Geremia G, Haklin M, Brennecke L. Embolization of experimentally created aneurysms with intravascular stent devices. AJNR Am J Neuroradiol 1994;15:1223-31

7. Lieber BB, Livescu V, Hopkins LN, et al. Particle image velocimetry assessment of stent design influence on intra-aneurysmal flow. Ann Biomed Eng 2002;30:768-77

8. Trager AL, Sadasivan C, Seong J, et al. Correlation between angiographic and particle image velocimetry quantifications of flow diverters in an in vitro model of elastase-induced rabbit aneurysms. J Biomech Eng 2009;131:034506

9. Damasio H. A computed tomographic guide to the identification of cerebral vascular territories. Arch Neurol 1983;40:138-42

10. Brinjikji W, Cloft HJ, Fiorella D, et al. Estimating the proportion of intracranial aneurysms likely to be amenable to treatment with the Pipeline embolization device. J Neurointerv Surg 2013;5:45-48

11. Appanaboyina S, Mut F, Löhner R, et al. Computational modelling of blood flow in side arterial branches after stenting of cerebral aneurysms. Int J Comput Fluid Dynamics 2008;22:669-76

12. Seong J, Wakhloo AK, Lieber BB. In vitro evaluation of flow diverters in an elastase-induced saccular aneurysm model in rabbit. J Biomech Eng 2007;129:863-72

13. Kallmes DF, Ding YH, Dai D, et al. A new endoluminal, flow-disrupting device for treatment of saccular aneurysms. Stroke 2007;38:2346-52

14. Kallmes DF, Ding YH, Dai D, et al. A second-generation, endoluminal, flow-disrupting device for treatment of saccular aneurysms. AJNR Am J Neuroradiol 2009;30:1153-58

15. Puffer RC, Kallmes DF, Cloft HJ, et al. Patency of the ophthalmic artery after flow diversion treatment of paraclinoid aneurysms. J Neurosurg 2012;116:892-96

16. Brinjikji W, Lanzino G, Cloft $\mathrm{HJ}$, et al. Patency of the posterior communicating artery after flow diversion treatment of internal carotid artery aneurysms. Clin Neurol Neurosurg 2014;120:84-88

17. Takahashi S, Tobita M, Takahashi A, et al. Retrograde filling of the anterior choroidal artery: vertebral angiographic sign of obstruction in the carotid system. Neuroradiology 1992;34:504-07

18. Morandi X, Brassier G, Darnault P, et al. Microsurgical anatomy of the anterior choroidal artery. Surg Radiol Anat 1996;18:275-80

19. Takahashi S, Suga T, Kawata Y, et al. Anterior choroidal artery: angiographic analysis of variations and anomalies. AJNR Am J Neuroradiol 1990;11:719-29

20. Matsushige T, Kiura Y, Sakamoto S, et al. Multiple antiplatelet therapy contributes to the reversible high signal spots on diffusionweighted imaging in elective coiling of unruptured cerebral aneurysm. Neuroradiology 2013;55:449-57

21. Hahnemann ML, Ringelstein A, Sandalcioglu IE, et al. Silent embolism after stent-assisted coiling of cerebral aneurysms: diffusionweighted MRI study of 75 cases. J Neurointerv Surg 2014;6:461-65

22. Yoon JW, Siddiqui AH, Dumont TM, et al. Feasibility and safety of Pipeline embolization device in patients with ruptured carotid blister aneurysms. Neurosurgery 2014;75:419-29

23. Hanley JA, Lippman-Hand A. If nothing goes wrong, is everything all right? JAMA 1983;249:1743-45 